\title{
Should Midazolam Drug-Drug Interactions be of Concern to Palliative Care Physicians?
}

\author{
Aleksandra Kotlinska-Lemieszek
}

Published online: 7 June 2013

(C) The Author(s) 2013. This article is published with open access at Springerlink.com

I read the article Drug Interactions in Dying Patients: A Retrospective Analysis of Hospice Inpatients in Germany, written by Frechen et al. [1] with great interest. In the palliative care setting, drug-drug interactions (DDIs) must be of special concern, especially in end-of-life care when the patient's condition and organ functions deteriorate, the number of drugs taken often exceeds ten, and monitoring of the treatment becomes difficult. In the article, the authors reviewed the main drug combinations that may give rise to DDIs in patients undergoing palliative care. However, I would like to also draw special attention to the risk of DDIs with benzodiazepines, and particularly midazolam, which is classified by the Federal Union of German Associations of Pharmacists (ABDA) database as a substance with a low potential for DDIs.

It is well recognized that benzodiazepines carry a risk of serious pharmacodynamic interactions with many drugs that exert CNS depressant effects. Some of them are substrates of cytochrome P450 (CYP)3A and other CYP enzymes that raise additional risks of pharmacokinetic interactions through that system. These include diazepam, alprazolam, clonazepam, flunitrazepam, clorazepate and midazolam. The latter is a short-acting benzodiazepine and a CYP3A4 probe substrate. It is available for oral and parenteral administration mostly subcutaneously and intravenously and used more commonly in the palliative care setting in patients with difficulty swallowing and when death approaches, in the treatment of pain, dyspnea, anxiety, agitation and, more importantly, for brief and continuous palliative sedation in the management of refractory

\footnotetext{
A. Kotlinska-Lemieszek ( $\square)$

Palliative Medicine Chair and Department, Karol Marcinkowski

University of Medical Sciences, Poznan, Poland

e-mail: alemieszek@ump.edu.pl
}

symptoms and intolerable suffering. The review of the literature shows that CYP3A inhibitors and inducers such as antifungal azoles (ketokonazole, itraconazole, fluconazole, voriconazole), erythromycin, ritonavir, rifampicin and carbamazepine, among others, significantly change the disposition of midazolam [2-8]. In one of the earlier studies of intravenous midazolam, the area under the plasma concentration-time curve (AUC) increased as much as fivefold after ketokonazole (strong CYP3A4 inhibitor) pretreatment, and intrinsic clearance decreased by $84 \%$ [3]. Surely, the inhibition of midazolam metabolism was greater with oral administration (increase of total bioavailability from 25 to $80 \%$ and 16-fold increase in AUC of midazolam) [3]. Such extensive alterations in midazolam pharmacokinetics should be expected to be of clinical relevance, which is supported by studies. The magnitude of the alterations in midazolam pharmacokinetics was well demonstrated in a study by Backman et al. [9], in which volunteers subsequently received itraconazole for 4 days and, after 2 weeks, rifampin (for a further 5 days). Midazolam was ingested before the first treatment, during and 4 days after itraconazole as well as 1 and 4 days after rifampin. During itraconazole treatment, the $\mathrm{AUC}_{0-\infty}$ of midazolam increased eightfold, with prolongation of its elimination half-life from 2.7 to $7.6 \mathrm{~h}$, while 1 day after rifampin treatment, the $\mathrm{AUC}_{0-\infty}$ was greatly reduced to $2.3 \%$ of the before-treatment value and $0.26 \%$ of the value during CYP inhibitor treatment (an approximately 400-fold change in the AUC). The midazolam AUC was still considerably decreased when determined 4 days after rifampin cessation ( $13 \%$ of the before-treatment value), which indicated that the risk of interactions outlasted the period of an inducer intake. In an interesting study, Hafner et al. investigated the pharmacokinetics of intravenous and oral midazolam after 14 days of co-administration of 
ritonavir (a potent CYP3A4 inhibitor) and St John's wort (a potent CYP3A4 inducer) [10]. The combined administration of the CYP3A4 inhibitor and inducer in that study resulted in a predominance of enzyme inhibition, with significant increases in the midazolam AUC to 180 and $412 \%$ of the baseline value for intravenous and oral administration, respectively. When measured 2 days after withdrawal of the two CYP3A4 precipitants, the AUC of oral and intravenous midazolam decreased to 6 and $33 \%$ of the level observed during combined administration, respectively, which reflects the prolonged effect of St John's wort on the metabolism of midazolam. This observation indicates even more complex outcomes of DDIs in clinical settings. The investigations clearly show a risk of considerable alterations in exposure to midazolam, also when used parenterally; it is important this be adequately recognized and dosages adjusted if required. In the clinical setting, other factors that might affect the pharmacokinetics and clinical effects of midazolam, including genetic polymorphism of CYP3A4/5 activity and deteriorating renal function in palliative care patients, among others, must be taken into account $[11,12]$.

Acknowledgments No funding was used to prepare this manuscript. Aleksandra Kotlinska-Lemieszek has no conflicts of interest directly relevant to the content of this letter.

Open Access This article is distributed under the terms of the Creative Commons Attribution Noncommercial License which permits any noncommercial use, distribution, and reproduction in any medium, provided the original author(s) and the source are credited.

\section{References}

1. Frechen S, Zoeller A, Ruberg K, Voltz R, Gaertner J. Drug interactions in dying patients: a retrospective analysis of hospice inpatients in Germany. Drug Saf. 2012;35(9):745-58.
2. Olkkola KT, Backman JT, Neuvonen PJ. Midazolam should be avoided in patients receiving the systemic antimycotics ketoconazole or itraconazole. Clin Pharmacol Ther. 1994;55:481-5.

3. Tsunoda SM, Velez RL, von Moltke LL, et al. Differentiation of intestinal and hepatic cytochrome P450 3A activity with use of midazolam as an in vivo probe: effect of ketoconazole. Clin Pharmacol Ther. 1999;66(5):461-71.

4. Yang J, Atkins WM, Isoherranen $\mathrm{N}$, et al. Evidence of CYP3A allosterism in vivo: analysis of interaction between fluconazole and midazolam. Clin Pharmacol Ther. 2012;91(3):442-9.

5. Saari TI, Laine K, Leino K, et al. Effect of voriconazole on the pharmacokinetics and pharmacodynamics of intravenous and oral midazolam. Clin Pharmacol Ther. 2006;79(4):362-70.

6. Olkkola KT, Aranko K, Luurila H, et al. A potentially hazardous interaction between erythromycin and midazolam. Clin Pharmacol Ther. 1993;53:298-305.

7. Backman JT, Olkkola KT, Ojala M, et al. Concentrations and effects of oral midazolam are greatly reduced in patients treated with carbamazepine or phenytoin. Epilepsia. 1996;37(3):253-7.

8. Backman JT, Olkkola KT, Neuvonen PJ. Rifampin drastically reduces plasma concentrations and effects of oral midazolam. Clin Pharmacol Ther. 1996;59(1):7-13.

9. Backman JT, Kivistö KT, Olkkola KT, et al. The area under the plasma concentration-time curve for oral midazolam is 400 -fold larger during treatment with itraconazole than with rifampicin. Eur J Clin Pharmacol. 1998;54(1):53-8.

10. Hafner V, Jäger M, Matthée AK, et al. Effect of simultaneous induction and inhibition of CYP3A by St John's Wort and ritonavir on CYP3A activity. Clin Pharmacol Ther. 2010;87(2):191-6.

11. Yamazaki H, Nakamoto M, Shimizu M, et al. Potential impact of cytochrome P450 3A5 in human liver on drug interactions with triazoles. Br J Clin Pharmacol. 2010;69(6):593-7.

12. Ahonen J, Olkkola KT, Takala A, Neuvonen PJ. Interaction between fluconazole and midazolam in intensive care patients. Acta Anaesthesiol Scand. 1999;43(5):509-14. 